\title{
A CONTRIBUIÇÃO DA BIBLIOTECA CONTEMPORÂNEA PARA A FORMAÇÃO DO LEITOR
}

Denize da Encarnação Pontes

Prof $^{a}$ da Rede Pública Municipal de Praia Grande

\section{RESUMO}

O presente artigo pretende contribuir para a reflexão sobre o papel da biblioteca no mundo contemporâneo e as novas práticas profissionais que estão surgindo a partir do uso das tecnologias de informação e comunicação. Também visa explicitar a importância em se manter vivo e renovado o espaço das bibliotecas públicas e escolares, como um lugar de disseminação da informação e incentivo a leitura, bem como enaltecer as funções específicas do auxiliar de biblioteca, delineando um trajeto mostrando que esse profissional, além de ser o responsável por executar as tarefas rotineiras de uma biblioteca ou de um centro de documentação, pode também atuar realizando atividades variadas em diferentes setores desde o atendimento até a apresentação do livro, tornando-se assim, uma peça fundamental para o bom funcionamento de uma biblioteca e um grande estimulador da leitura.

Palavras-Chave: Biblioteca; informação; tecnologia; novas práticas. 


\section{1- INTRODUÇÃO}

A sociedade está passando por um período de transformações tecnológicas e tem enfrentado os consequentes impactos sociais gerados por estas. Essa nova tecnologia possibilita que diversas tarefas sejam realizadas por máquinas, havendo um redimensionamento da atividade humana neste contexto.

Mesmo assim, os impactos sociais causados pelas tecnologias não são um fato novo nas bibliotecas, onde durante toda história, esses locais passaram por diversas transformações.

Vale ressaltar, que no passado, as bibliotecas repletas de livros grandes e pesados, eram administradas por monges e frequentadas por membros da Igreja.

Sendo assim, a palavra biblioteca historicamente teve um caráter restritivo e estático. Os livros de difícil reprodução e mobilidade tornaram a biblioteca um templo e o bibliotecário seu guardião. Esta imagem manteve-se até pouco tempo.

Porém com a introdução das novas tecnologias de informação e comunicação, essa configuração começa dar sinais de mudança onde, com o decorrer do tempo, esse caráter restrito cedeu lugar a uma biblioteca fornecedora de informação em diferentes formatos, podendo ser acessada por qualquer pessoa.

Com isso, surge o auxiliar de biblioteca, que deixou de ser um erudito, guardião dos livros para se tornar um profissional mediador no processo de busca da informação podendo ser visto como um educador do usuário e estimulador de leitura.

Embora exista a crença de que uma biblioteca seja um local que demande pouco trabalho, quando observamos o cotidiano de bibliotecas e outros centros de informação nos deparamos com uma grande variedade de atividades a serem realizadas, onde pesquisas nos mostram, que são muitas as atribuições da função de auxiliar de biblioteca, entre as principais e mais rotineiras estão: fazer cadastro de novos usuários da biblioteca; orientar usuários sobre o funcionamento e recursos da biblioteca; administrar empréstimos e devoluções da biblioteca; auxiliar no serviço de comutação bibliográfica; auxiliar na seleção e aquisição de obras ou documentos para o acervo; auxiliar na restaurar e encadernar material danificado ou rasurado; digitalizar materiais; manter a organização do acervo; localizar obras e documentos; executar pesquisas e levantamentos bibliográficos etc.

Portanto, percebe-se que esse profissional vem para colaborar com a melhoria de toda a categoria bibliotecária e como um mediador entre o livro e o público.

Mas, de maneira geral, a maioria das pessoas não está habituada a lidar com profissionais dessa área, nem tão pouco a frequentar esses ambientes. Talvez, de modo triste para a cultura geral em nosso país, isso se deva ao baixo índice de escolaridade com qualidade e as condições de acesso ao livro, podendo ser esses fatos, a raiz do problema.

Dessa forma, e referindo-se ao modo como muitos brasileiros se tornam leitores, Maués 2002, amplia a compreensão sobre o problema quando cita: 
Muitas vezes esse é um leitor quase heróico, que consegue de alguma formaem igrejas, por empréstimos de amigos, por meio da escola ou das poucas e precárias bibliotecas existentes, superar os obstáculos que lhe são impostos e chegar até o livro, contra quase todas as probabilidades. (MAUÉS,2003, p.65).

Nesse sentido, a proposta deste trabalho é justamente fazer um estudo a respeito da existência das novas dinamizações das bibliotecas e a participação das mesmas na interação com seus usuários, com foco em apresentar a importância de incentivar o hábito de desfrutar e conhecer uma biblioteca, valorizando os profissionais que nela atuam, tendo em vista desenvolver uma sociedade leitora.

\section{2- CONCEITO BÁSICO DAS BIBLIOTECAS}

\section{2-1 BREVE HISTÓRICO}

Tida como um depósito de livros, aos quais nem todos tinham acesso, as bibliotecas eram um lugar místico que abrigava e aprisionava as informações. No passado eram administradas por monges e frequentadas por membros da Igreja. Porém, ao longo da história, elas passaram por diversas transformações, e com o passar do tempo, seu caráter restrito passou a dar lugar a uma biblioteca fornecedora de informação em diferentes formatos, podendo ser acessada por qualquer pessoa.

Já as bibliotecas da Antiguidade e do período medieval eram similares. Ambas se constituíam locais de armazenamento de documentos, com sistemas precários de recuperação e acesso. E na Idade Média, onde o centro social e econômico da população era a Igreja, o clero era quem comandava as bibliotecas, que eram de difícil acesso para a população. As bibliotecas medievais se encontravam dentro de mosteiros, e o acesso ao material era permitido apenas aos pertencentes às ordens religiosas ou pessoas aceitas por estas.

Durante a Idade Média surgiram as bibliotecas universitárias, pouco antes do Renascimento. A princípio elas estavam ligadas às ordens religiosas, mas começavam a ampliar o conteúdo temático além da religiosidade. Essas bibliotecas são as que mais se aproximam do conceito atual de biblioteca como espaço de acesso e disseminação de informação. Com a chegada do Renascimento, difundiu-se na Europa a tecnologia dos tipos móveis, criada por Gutenberg. Isso permitiu uma nova situação de acessibilidade dos livros (de papel e impresso), e acabou sendo um estímulo ao conhecimento.

O crescimento deste ciclo aumentou a relação entre a universidade, a biblioteca e seus leitores. A Renascença trouxe mudanças para a biblioteca universitária que aos poucos ganha mais espaço, autenticidade e autonomia, estendendo sua visão de democratização da informação às bibliotecas posteriores a ela. A biblioteca moderna rompeu os laços com a igreja e estendeu a todos a possibilidade de acesso aos livros. 
Hoje, com os recursos da informática, é possível converter elementos da realidade física e material para a realidade virtual, facilitando a transferência de informação. A introdução das tecnologias de informação e comunicação (TICs) trouxe alterações na rotina e no ambiente de trabalho do bibliotecário, no perfil do profissional e no processo de interação entre os usuários e os bibliotecários. O objetivo de uma biblioteca hoje, é disponibilizar informação, e o meio eletrônico é um meio em que é possível armazenar e oferecer um maior número de informações.

Essa biblioteca nascida na Renascença também trouxe o bibliotecário como um profissional reconhecido, que deixa de ser um erudito e passa a se tornar um mediador no processo de busca da informação. Com a implantação dos sistemas informatizados, as interações entre bibliotecários e usuários passam por mudanças significativas, exigindo um novo perfil de bibliotecário mais qualificado.

Sendo assim, para exercer esta profissão é preciso fazer o Bacharelado em Biblioteconomia e se inscrever no Conselho Regional de Biblioteconomia. Este profissional trabalha como um administrador de informações. Suas funções incluem: catalogar e guardar as informações, orientar sua busca e seleção. Também analisar, sintetizar e organizar livros, revistas, documentos, fotos, filmes e vídeos. É sua responsabilidade planejar, implementar e gerenciar sistemas de informação, além de preservar os suportes (mídias) para que resistam ao tempo. Ele ainda pode prestar serviços de assessoria e consultoria na área de informação e redes e sistemas de informação.

\section{2-2 TIPOS DE BIBLIOTECA}

O tipo de biblioteca é determinado pelas funções e serviços oferecidos, pela comunidade atendida e pelo seu vínculo institucional. Existem vários tipos, como por exemplo: a Biblioteca Pública, cujo objetivo é atender por meio de seu acervo e serviços, os diferentes interesses de leitura e informação da comunidade em que está localizada. Ela colabora para ampliar o acesso, de forma gratuita, à informação, à leitura e ao livro e atende a todos os públicos (crianças, jovens, adultos, etc.) seguindo os preceitos estabelecidos no Manifesto da IFLA/Unesco sobre Bibliotecas Públicas. Geralmente são criadas e mantidas pelo Estado (Município, Estado ou Federação). Algumas bibliotecas públicas possuem acervos especializados, e são denominadas Bibliotecas Públicas Temáticas, outras oferecem serviços especializados, e são identificadas pelo público, como Biblioteca Pública Infantil. Além da biblioteca pública existem outros tipos de biblioteca. Sob esta questão Barker e Escarpit( 1975, p.675) ressaltam que:

Existem vários tipos de biblioteca: bibliotecas nacionais e públicas, nas quais o edifício e o estoque são pagos com verbas públicas, como também os salários do pessoal geralmente preparado em cursos especializados. Nelas a utilização de todo esse material é feita gratuitamente pelo público; bibliotecas universitárias, para uso de professores e estudantes; bibliotecas escolares; bibliotecas especializadas, que fazem parte de instituições profissionais ou oficiais; bibliotecas industriais, mantidas por empresas para fornecer material de referencia e talvez livros técnicos aos funcionários, bibliotecas comerciais, que emprestam livros mediante pagamento de uma taxa anual de uma pequena taxa de aluguel por livro. 
Também há a Biblioteca Comunitária, sem vínculo direto com o Estado, é criada e mantida pela comunidade local. Ponto de Leitura. Já a Biblioteca Nacional tem a função de reunir e preservar toda produção bibliográfica do país. Cada país possui uma Biblioteca Nacional. Toda produção bibliográfica do país deve ser enviada para a Biblioteca Nacional, no Brasil, ela está sediada no Rio de Janeiro.

E finalizando, pode-se citar também o Centro de Referência: São especializadas e atuam com o foco no acesso, disseminação, produção e utilização da informação para um determinado público. Muitos centros não possuem acervo próprio e trabalham com a referenciação de documentos sobre determinados assuntos.

Nesse sentido, percebemos que a importância que cada tipo de biblioteca tem quando desempenha com firmeza o seu papel na sociedade, pois, além de propiciar a aquisição do conhecimento, tem a função de levar a discussão critica da realidade.

Além disso, para Milanesi (1988, p.93) a biblioteca é também, um instrumento de leitura do cotidiano com os seus conflitos e problemas. Então, a biblioteca não pode ser algo distante da população como um posto médico que ele procura quando tem dor. Ela deve ser um local de encontro e discussão, um espaço onde é possível aproximar-se do conhecimento registrado e onde se discute criticamente esse conhecimento.

\section{3- CONCEITOS DE BIBLIOTECONOMIA}

É evidente que para manter sua contribuição social na formação de leitores, as bibliotecas tradicionais (públicas, escolares, particulares etc.) necessitam ser aprimoradas visando um aumento de visitações e permanência de crianças, jovens e adultos, para que assim a leitura deixe de ser um privilégio de poucos e se torne um direito de todos.

Por conta disso, cursos especializados foram criados e instituídos no sentido de atender as demandas de um público mais exigente frente as nova era tecnológica.

No Brasil, a biblioteconomia como curso de graduação é considerada como uma das ciências da informação devido seu caráter interdisciplinar e seu objeto de estudo. Ela é a ciência que estuda os aspectos da representação, sistematização, uso e disseminação da informação através de serviços e produtos informacionais. A biblioteconomia trata da análise, planejamento, implementação, organização e a administração da informação em bibliotecas, banco de dados, centros de documentação, entre outros.

Com relação ao bibliotecário, vale ressaltar e enaltecer o já citado anteriormente, que ele é um profissional liberal (bacharel, mestre ou doutor) que trata a informação e a torna acessível ao usuário final, independente do suporte informacional. Ele domina técnicas de classificação, organização, conservação e divulgação do acervo de bibliotecas ou centros de documentação. Pode atuar na criação e manutenção de arquivos digitais e montagem de banco de dados em computadores. Este profissional, além de catalogar e armazenar as informações, também orienta na busca e seleção, analisa e organiza livros, revistas, documentos, fotos, filmes e 
vídeos. Suas responsabilidades incluem planejar, implementar e gerenciar sistemas de informação, além de preservar os suportes para que resistam ao tempo.

\section{3-1 LEIS DA BIBLIOTECONOMIA}

A biblioteconomia possui cinco leis ou princípios que são consideradas a base para todas as atividades biblioteconômicas, cada lei defende uma postura profissional dinâmica para aqueles que lidam com a informação. As cinco leis são simples e permitem que o profissional possa compreender a função de sua profissão dentro de um contexto social, permitindo se definir critérios e princípios de ação. Cada lei desencadeia a próxima, fazendo com que ocorra um processo cíclico e dinâmico. Sendo assim, segue-se a seguinte ordem:

$1^{a}$ Lei: Os livros são para serem usados. Esta primeira lei discute questões que envolvam a democratização da informação. Segundo Ranganathan, matemático e bibliotecário da Índia , considerado o pai da biblioteconomia no país, a organização das obras em uma biblioteca deve ser feita por assunto. Ele percebeu, em sua experiência, que a maioria dos leitores procurava por assuntos específicos, independente de autor. A partir daí surgiu a ideia de uma primeira organização por sequência de assuntos.

$2^{a}$ Lei: A cada leitor seu livro. Esta lei introduz o conceito de que os livros são para todos, assim como, o conceito de que a educação é para todos. Ela foi responsável por tornar a biblioteca um espaço democrático de acesso à informação. Esta lei prioriza o leitor, uma vez que se todos os livros sobre um assunto estiverem reunidos será mais fácil para ele. De acordo com esta lei, o importante é permitir a acessibilidade à informação.

$3^{\text {a }}$ Lei: A cada livro seu leitor. Esta lei diz respeito ao esforço por parte da biblioteca por tornar cada livro disponível para que possa ser localizado pelo usuário., ou seja cada leitor, devido à sua formação, visão de munda, crença, possui necessidades diferentes e é necessário que o bibliotecário possa servir como um elemento facilitador entre cada usuário e o material (livro/documentário/informação) adequado.

$4^{\mathrm{a}}$ Lei: Poupe o tempo do leitor. Esta lei discute questões ligadas à organização do acervo: métodos, técnicas e instrumentos adequados que possam atender às necessidades dos leitores, permitindo que os materiais possam chegar ao usuário em menor tempo possível. A quarta lei se reflete nas medidas adotadas pela biblioteca para que o usuário encontre o que procure no tempo em que o documento lhe seja útil. Logo, o bibliotecário deve ser um agilizador de informação. Esta lei incentiva o bibliotecário a criar novas formas de organização.

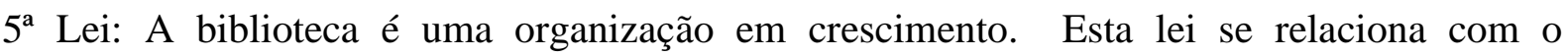
planejamento e organização das bibliotecas tendo em vista seu desenvolvimento. A produção do conhecimento é um ato contínuo do ser humano, portanto a biblioteca é uma organização em crescimento. A todo momento surgem novos assuntos, assim como novos usuários com características diversas, exigindo que o bibliotecário repense sobre as práticas e instrumentos utilizados e sobre as atividades realizadas. 


\section{3-2 AS BIBLIOTECAS DIGITAIS E TECNOLOGIA DA INFORMAÇÃO}

Com o crescimento constante de conhecimentos e informações cada vez mais veloz, as bibliotecas tradicionais não conseguem suprir as necessidades informacionais de seus usuários, que passam a ser usuários eletrônicos, aptos a incorporar mecanismos digitais a suas pesquisas e buscas. O uso de Tecnologias de Comunicação e Informação (TCI) está atrelado a Biblioteca Digital e ao Gerenciamento Eletrônico de Documentos.

Um dos diferenciais da biblioteca digital é que a informação que ela contém existe apenas na forma digital. Isto é, a informação pode ser acessada remotamente por meio de redes de computadores. As bibliotecas digitais trabalham com armazenamento, conservação e recuperação de informação em meio eletrônico. Logo, as TCIs são uma peça fundamental para contribuir com a gestão de documentos eletrônicos.

O conceito de biblioteca digital, difundido a partir da década de 1990, veio acarretar grande vantagem ao acesso do fluxo de informação disseminada na internet. A informação organizada nesses suportes permitiu o acesso a uma grande quantidade de informações e conhecimentos.

Vale ressaltar que a Era Digital se iniciou após a Revolução Industrial e o período entre guerras, e inclui, dentre outros aspectos, a criação e evolução de novos suportes informacionais eletrônicos. Mas a informação contida em meio eletrônico é dispersa e muitas vezes fragmentada. Assim, houve a necessidade de se criar formas eficazes e eficientes de organizar e disseminar informações, para que sejam acessadas via Web, de forma segura e confiável.

Com as bibliotecas digitais o usuário pode fazer sua consulta e obter as informações do seu próprio computador, necessitando apenas de conexão à rede. A biblioteca digital é a evolução eletrônica da biblioteca tradicional.

Alguns exemplos de biblioteca digital são: Portal do Domínio Público; Biblioteca Nacional Digital Brasil e a Biblioteca Digital do Senado Federal.

\section{4- METODOLOGIA}

Para a elaboração deste trabalho, foi utilizada a metodologia de pesquisa descritiva e bibliográfica, realizando de modo constante a análise da literatura, compreendendo os trabalhos em que o assunto era pertinente a área de estudo e pesquisa, apresentados em artigos acadêmicos; livros e sites da internet.

Portanto, as principais referências foram pautadas nos estudos de grandes pesquisadores que se preocuparam com as abordagens da importância das bibliotecas na formação de leitores e na disseminação da informação.

Em razão do âmbito abrangente, o atual trabalho buscou compreender também o papel do auxiliar de bibliotecas como incentivador da leitura, despertando assim, o interesse pelas histórias e pelos livros nas pessoas que das bibliotecas se utilizam. 
Espera-se, que esta pesquisa possa servir também de apoio para que educadores e professores utilizem novas práticas pedagógicas e que consigam desenvolver em seus alunos, o gosto e o prazer em ouvir e conhecer as histórias.

\section{CONSIDERAÇÕES FINAIS}

Após este estudo realizado, percebemos que a introdução das tecnologias de informação e comunicação nas unidades de informação trouxe impactos nas bibliotecas e novas formas de sociabilidade entre os bibliotecários e os usuários. Elas são percebidas pelos bibliotecários como elementos facilitadores na execução das tarefas exigidas pela rotina do seu trabalho, além de auxiliarem os usuários no processo de busca das informações e do conhecimento, tornandoos mais autônomos.

Em tempos remotos, as atividades dos bibliotecários voltavam-se para o acervo da biblioteca como única fonte de informação. Hoje, elas estão centradas na informação, independente do suporte em que esteja registrada. As tecnologias facilitam a reprodução da informação nessa variedade de formatos, ocasionando uma grande avalanche informacional. Nessa nova configuração, a biblioteca apresenta-se como um centro dinâmico da informação.

A inserção das tecnologias na vida da biblioteca e seus profissionais estão transformando substancialmente as concepções dos bibliotecários e dos usuários acerca da biblioteca e o seu papel. Nesse novo contexto, espera-se que esta pesquisa contribua para uma reflexão da nova visão de biblioteca contemporânea, sendo identificada como um local "moderno" onde se disponibiliza informação, e o bibliotecário como seu disseminador, atuante e consciente de suas responsabilidades como agente transformador e colaborador de uma sociedade mais ética e cidadã. 


\section{BIBLIOGRAFIA}

BARKER, Ronald E.; ESCARPIT, Robert. A fome de ler. Rio de Janeiro: Editora da Fundação Getulio Vargas, 1975.

BAMBERGER, Richard. Como incentivar o habito de leitura. Editora Ática, $19915^{\circ}$ edição.

EL FAR, Alessandra. O livro e a leitura no Brasil. Rio de Janeiro: Jorge Zahar Ed.2006.

FOUCAMBERT, Jean. A leitura em questão - Porto Alegre:Artes Médicas, 1994. MAUÉS, Flamarion. A exclusão da leitura. Revista Teoria e Debate. São Paulo, n. 50, fev./mar./abr.2002.

MILANESE, Luis. O que é biblioteca. São Paulo: Editora Brasiliense. $5^{\circ}$ edição, 1988.

SILVA, Ezequiel T. Leitura e realidade brasileira. Porto alegre: mercado aberto, 1997.

SCHWARCZ, Lilia M. A longa viagem da biblioteca dos reis. São Paulo: companhia das

letras, 2002. 